\title{
Development of Methodology for Measurements of Residual Stresses in Welded Joint Based on Displacement of Points in a Coordinated Table
}

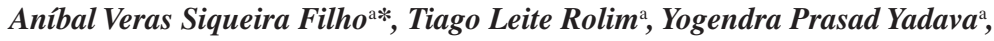 \\ Francisco Ilo Bezerra Cardoso ${ }^{\mathrm{b}}$, Pablo Batista Guimarães,
} Theophilo Moura Maciel ${ }^{\mathrm{d}}$, Ricardo Artur Sanguinetti Ferreira ${ }^{\mathrm{a}}$

\author{
${ }^{a}$ Departamento de Engenharia Mecânica, Universidade Federal de Pernambuco - UFPE, \\ Av. Acadêmico Hélio Ramos, s/n, Cidade Universitária, CEP 50740-530, Recife, PE, Brasil \\ ${ }^{\mathrm{b}}$ Departamento de Engenharia Mecânica, Escola Politécnica, Universidade de Pernambuco - UPE, \\ Rua Benfica, 455, Madalena, CEP 50720-001, Recife, PE, Brasil \\ 'Instituto Federal de Educação, Ciência e Tecnologia de Pernambuco - IFPE, Av. Professor Luiz Freire, \\ 500, Cidade Universitária, CEP 50740-540, Recife, PE, Brasil \\ ${ }^{\mathrm{d}}$ Unidade Acadêmica de Engenharia Mecânica - UAEM, Centro de Ciências e Tecnologia-CCT, \\ Universidade Federal de Campina Grande - UFCG, Rua Aprigio Veloso, 882, Bodocongó, CP 10069, \\ CEP 58429-900, Campina Grande, PB, Brasil
}

Received: November 16, 2011; Revised: October 6, 2012

\begin{abstract}
Residual stresses in a welded joint of ASTM A131 grade AH32 steel was measured either by the X-ray diffraction or by displacements of referenced points measured on a coordinate measuring machine before and after heat treatment. For all tests, the welding was performed with Shielded Metal Arc Welding, vertical-up position, by a certified welder. After welding, some specimens were subjected to marking, made through small holes evenly spaced and mapped on a coordinate measuring machine. After labeling, the samples were subjected to heat treatment at temperatures nearby recrystallization. After heat treatment, the samples were subjected to new measurements by coordinate measuring machine to evaluate the displacements of the points produced by the recrystallization. In parallel, residual stress measurements were made by XRD for validation of this new methodology. The results obtained either by X-ray or by coordinate measuring machine showed a good correlation between the two measurement methodologies employed.
\end{abstract}

Keywords: residual stress, coordinate measuring machine, X-Ray diffraction

\section{Introduction}

Traditional methods of welding produce changes in the surface layer proportional to the severity of process conditions. The welding process tends to generate high temperatures and excessive plastic deformation.

Residual stresses are internal stresses that exist in bodies that are at rest, at a steady state and subjected to standard conditions of temperature, in the absence of external loads and body forces. They arise in any material or component due to the manufacturing process or subsequent processing and can hardly be predicted with accuracy, unless you know the whole story of the component ${ }^{1}$.

Under the metrological aspect residual stresses can be considered as macroscopic quantities, static and whose range of occurrence varies from zero to up to the yield stress values of the material. These fields of residual stresses arising from much of the beneficiation processes can be tensile or compressive and are generally triaxial and vary from point to point, especially given the complexity of geometries.

*e-mail: anibal_siqueira@yahoo.com.br
In practice the magnitudes are measures commonly two principal stresses acting on the surface of the part and its main direction.

Knowing the level of residual stresses, in engineering is primarily a safety factor to avoid problems of accidents and disasters. Quantification of residual stress state present in a component, i.e., its magnitude, direction and distribution makes possible the material's performance determination under different conditions of static or dynamic loading. This knowledge is always beneficial and essential for the optimal design, weight reduction and cost reduction. In some situations, it is desirable to know the level of residual stress simply to describe processes that normally introduce large amounts of residual stresses, such as blasting, welding processes, cold working, casting and heat treatment among others ${ }^{2}$.

The most comfortable way to determine the level of residual stresses existing in a component is through analytical or numerical models. The biggest problem in the applications of theoretical or numerical methods is 
that the events that cause the development of residual stresses show large variations either in mechanical or in metallurgical processes involved are unknown. However, in most situations, this practice is unworkable and experimental methods are of great importance ${ }^{3}$.

In this study, a new experimental method was evaluated in which specimens of welded joints were prepared and performed in a coordinate measuring machine to measure the displacement of points, followed by residual stresses calculation. The results were compared with those obtained by the method of ray diffraction $-X$, in order to validate the new method with coordinate measuring machine.

\section{Material and Methods}

The specimens used in this experimental method were plates of ASTM A131 grade AH32 shipbuilding steel with dimensions of $200.00 \mathrm{~mm} \times 200.00 \mathrm{~mm} \times 19.00 \mathrm{~mm}$, split with bevel angle of 25 degrees.

The mechanical properties ${ }^{4}$ and chemical composition ${ }^{5}$ of the base metal are presented in Tables 1 and 2, respectively.

The filler metal was the shielded electrode E7018, AWS/ASME SFA 5.16, with a diameter of $3.25 \mathrm{~mm}$. The mechanical properties and chemical composition 'on welded' condition of weld metal are presented in Tables 3 and 4 , respectively.

The welding apparatus used in this work was a source of tension commonly used in shielded metal is welding: The equipment operates according to the current range of 90-150A (CC+) and the open circuit voltage of 20-30V. The welding was performed by a qualified welder (ITEP $N^{\circ}$ 109436, Signet S2, 6G).

Table 1. Mechanical properties of base metal ${ }^{2}$.

\begin{tabular}{ccc}
\hline & $\begin{array}{c}\text { Yield strength } \\
\left(\mathbf{N} \cdot \mathbf{m m}^{-2}\right)\end{array}$ & $\begin{array}{c}\text { Endurance limit } \\
\left(\mathbf{N} \cdot \mathbf{m m}^{-2}\right)\end{array}$ \\
\hline $\begin{array}{c}\text { ASTM } \\
\text { AH32 }\end{array}$ & $315 \mathrm{~min}$. & $440-590$ \\
\hline
\end{tabular}

Table 2. Chemical composition of base metal ${ }^{3}$.

\begin{tabular}{cc}
\hline Chemical element & ASTM AH32 \\
\hline$\% \mathrm{C}$ max. & 0.18 \\
$\%$ Mn max. & 0.9 \\
$\% \mathrm{P}$ max. & 0.04 \\
$\% \mathrm{~S}$ max. & 0.04 \\
$\% \mathrm{Al}$ & 0.06 \\
$\% \mathrm{Ni}$ & 0.4 \\
$\% \mathrm{Cr}$ & 0.25 \\
$\% \mathrm{Si}$ & 0.1 \\
\hline
\end{tabular}

Earlier, during experimental work, preliminary tests were performed in order to find an ideal welding current higher than the transition current with the objective of getting the best mode of metal transfer in welding performed. For preliminary testing, the welding parameters used are presented in Table 5.

The welding was performed on butt joints with a $\mathrm{V}$ notch, being two plates with bevel angles of 25 degrees. During welding, vertical-up position was used. The steel surfaces for welding were abraded in order to remove the oxides formed during the hot rolling of the sheets.

The plates were welded in an open root of $3.25 \mathrm{~mm}$. Each sample was carried out by performing about ten passes, i.e. one being the root, one for reinforcement, five for filling and other three for final surface finishing. After completion of each pass, the weld slag was removed using a wire brush.

Under these conditions, four specimens of ASTM A131 grade AH32 welded steel plates were produced.

After welding, the samples were submitted to a process of electrolytic etching, to remove a thin layer of material (in the order of tenths of a millimeter) for elimination of possible residual stresses induced by prior manufacturing and cleaned in a solution of nitric acid and alcohol. The removal of the thin surface layer was carried out with the device, shown in Figure 1, consisting of a PVC tube $10 \mathrm{~mm}$ in diameter is filled with a solution of $10 \%$ hydrochloric acid. A silicone rubber for high temperature was placed at the end of the tube to make the seal between the PVC pipe and the surface of steel sheet. The current value was $19 \mathrm{~A}$ and the etching time was 20 minutes for each specimen.

Thirteen points were considered in this study. These points are at a distance $2.5 \mathrm{~mm}$ and $5.0 \mathrm{~mm}$ from weld fillet were previously mapped following schema shown in Figure 2 and 3. Three points were discard because of uncertainties do will be described below.

The residual stresses were measured in the transverse and longitudinal directions by the X-ray diffraction method.

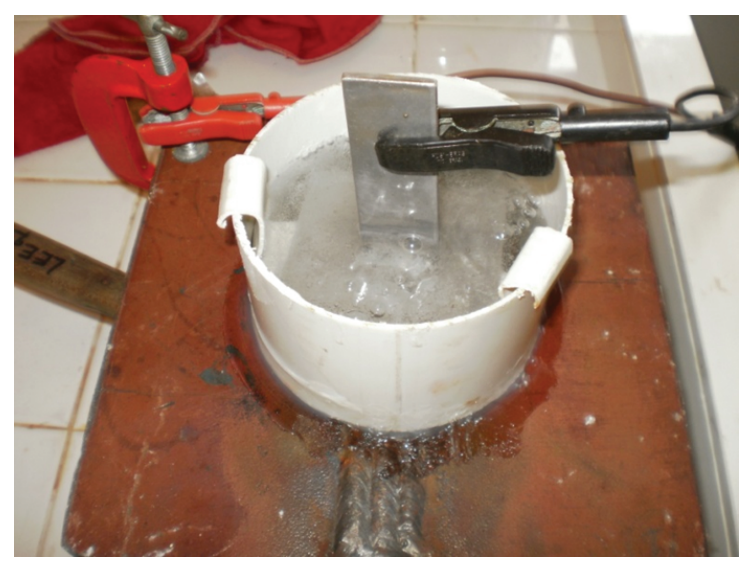

Figure 1. System electro polished.

Table 3. Mechanical properties of weld metal, according to AWS SFA 5.14

\begin{tabular}{cccc}
\hline & Charpy $($ V-notch - resistance $)$ & Endurance limit $(\mathbf{M P a})$ & Stretching $(\%)$ \\
\hline E7018 & $-30{ }^{\circ} \mathrm{C}$ & $530-590$ & $27-32$ \\
\hline
\end{tabular}


Table 4. Chemical composition of weld metal, according to AWS SFA 5.1 $1^{4}$.

\begin{tabular}{cc}
\hline Chemical element & E7018 \\
\hline$\% \mathrm{C}$ & 0.07 \\
$\% \mathrm{Mn}$ & 1.30 \\
$\% \mathrm{Si}$ & 0.50 \\
\hline
\end{tabular}

Table 5. Welding parameters.

\begin{tabular}{cc}
\hline Experiment & Coated electrodes \\
\hline Voltage in the Root $\left(\mathrm{V}_{\mathrm{RZ}}\right)$ & 26 \\
Voltage in the Reinforcement $\left(\mathrm{V}_{\mathrm{RE}}\right)$ & 26 \\
Voltage for Finish $\left(\mathrm{V}_{\mathrm{AC}}\right)$ & 26 \\
Current in the Root $\left(\mathrm{A}_{\mathrm{RZ}}\right)$ & 90 \\
Current in the Reinforcement $\left(\mathrm{A}_{\mathrm{RE}}\right)$ & 128 \\
Current for Finish $\left(\mathrm{A}_{\mathrm{AC}}\right)$ & 130 \\
Energy $\left(\mathrm{J} / \mathrm{mm}^{-1}\right)$ & $495-1198$ \\
\hline
\end{tabular}

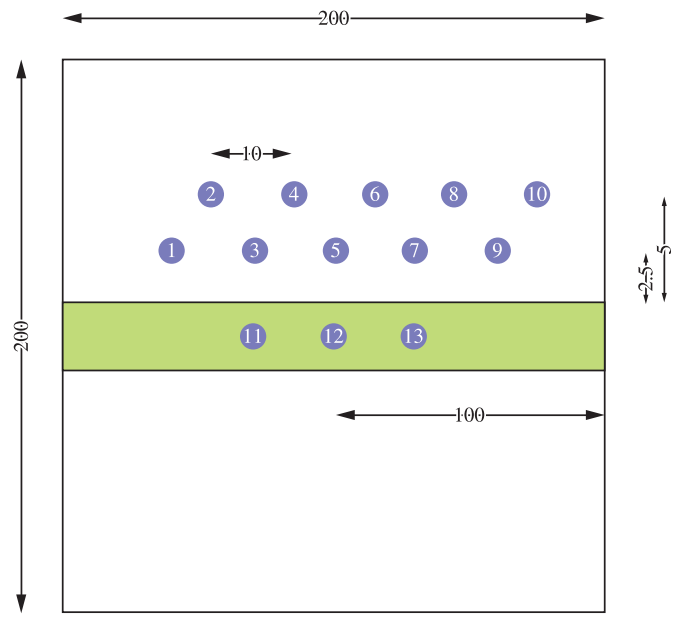

Figure 2. Schema of the points previously mapped.

For measurements of residual stresses a portable X-ray diffractometer was used. For the highest peak variation $(\Delta \theta)$ in the crystal lattice, the highest possible angle $(\theta)$ was chosen to determine the diffraction peak. Lu et al. ${ }^{7}$ mentioned that an excellent condition of analysis is the determination of the deformation of $\{211\}$ planes in ferritic or martensitic steel. In addition, a monochromatic beam with a wavelength of $\lambda=2.2911 \AA(\mathrm{Cr}-\mathrm{K}) \alpha$ was used during $\mathrm{X}$-ray diffraction patterns. The operating voltage was $25 \mathrm{kV}$ and current of $50 \mathrm{~mA}$. The method used was the sen $2 \psi$, with measurement of $\psi=0^{\circ}, 20^{\circ}, 30^{\circ}, 35^{\circ}$ and $45^{\circ}$. The joint X-ray/detector tube was mounted on the specimen to be measured. Commercial software was used for X-ray diffraction patterns, followed by calculation of the longitudinal and transversal of the residual stresses.

Following x-ray measurements, small holes with a 3,125 $\mathrm{mm}$ diameter and 2,0 $\mathrm{mm}$ deep, were drilled in previously mapped points which were referenced in a

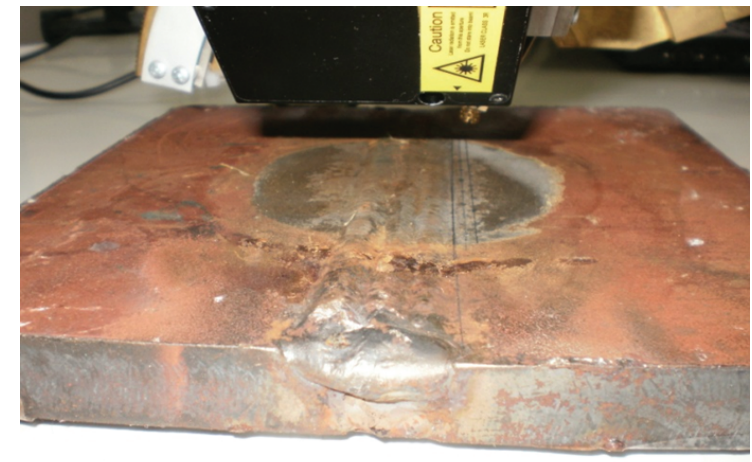

Figure 3. Marking of the points studied in X-ray diffractometer.

coordinate measuring machine. Finally, after heat treatments (annealing below the recrystallization temperature of the material) the displacements of the small holes associated with longitudinal and transverse strain were measured in a coordinate measuring machine.

Based on values of the holes displacements, the residual stresses were calculated in longitudinal and transverse directions, considering the Equations 1 and 2, according to Okumura $^{8}$.

$$
\begin{gathered}
\sigma_{x}=\frac{E}{1-v^{2}}\left(\varepsilon_{x}+v \varepsilon_{y}\right) \\
\sigma_{y}=\frac{E}{1-v^{2}}\left(\varepsilon_{y}+v \varepsilon_{x}\right)
\end{gathered}
$$

where:

- $\sigma_{x} \rightarrow$ Longitudinal residual stress - direction of the weld $[\mathrm{Pa}]$;

- $\sigma_{\mathrm{y}} \rightarrow$ Transverse residual stress - direction normal to the weld line $[\mathrm{Pa}]$;

- $\varepsilon_{\mathrm{x}} \rightarrow$ Deformation in the direction of welding;

- $\varepsilon_{\mathrm{y}} \rightarrow$ Deformation in the direction of Normal strain at the weld line;

- $v \rightarrow$ Poisson's ratio;

- $\mathrm{E} \rightarrow$ Elasticity module.

During calculations, values of 207.000 MPa and 0,30, were used for E and $v$, respectively ${ }^{9}$.

\section{Results and Discussion}

Measurements of longitudinal and transverse strains in the ten points in HAZ were made both by diffractometer and coordinate machine, which presented compressive values, independent of the distances from the welding fillet. These results are in agreement with Guimarães et al. ${ }^{10}$ who worked with simulated welding process based on the finite element method to study the temperature field as a basis for predicting levels of residual stresses in a welded joint. Results showed that the evolution of the field temperature as a function of time across HAZ, with values ranging from 766 to $1187^{\circ} \mathrm{C}$, which approximates the proportion of the 
weld, and finding the results of residual stresses in these points with behavior very similar to that presented in this paper. Besides, George et al. ${ }^{11}$ working with an orbital TIG welding process produced similar results. Welding a thin tube thickness, these authors found at the top in the HAZ, compressive residual stresses whose values were around -150 to $-100 \mathrm{MPa}$. Due to the tourniquet effect, the lower trative strains showed the same order of magnitude. In our case, the tourniquet effect was not observed, considering the thickness of our plate, and the restrictions imposed by welding.

For longitudinal residual stress Figure 4 X-ray measurents present values between -100 and $-150 \mathrm{MPa}$ for points at a distance $2.5 \mathrm{~mm}$ from weld fillet. Similar behaviors were observed for coordinate machine measurements in which present values between -125 and $-175 \mathrm{MPa}$. For points at a distance $5.0 \mathrm{~mm}$ from weld fillet, coordinate machine measurements present values around $-150 \mathrm{MPa}$ (Figure 5). X-ray measurements present values between -150 and $-180 \mathrm{MPa}$.

The results of longitudinal residual stresses obtained by coordinate machine measurements, relating to the displacement of points 1, 2, 3, 4, 6, 8 and 9 of Figures 4 and 5 , are compared with measurements of X-ray diffraction. Coordinate machine measurements are within the error limits of X-ray diffraction. At point 5, 7 and 10 the results differ somewhat between the methods, less worrisome because both methods have their limitations, such as geometric errors, diffraction hampered by impurities in the metal, among others.

Measurements for transverse residual stress in points at a distance $2.5 \mathrm{~mm}$ from weld fillet are shown in Figure 6. X-ray measurements present values between -175 and $-250 \mathrm{MPa}$. Coordinate machine measurements present values between -50 and $50 \mathrm{MPa}$. The difference between these methods revealed that a shape factor must be considered in coordinate machine measurements in order to approach the X-ray results.

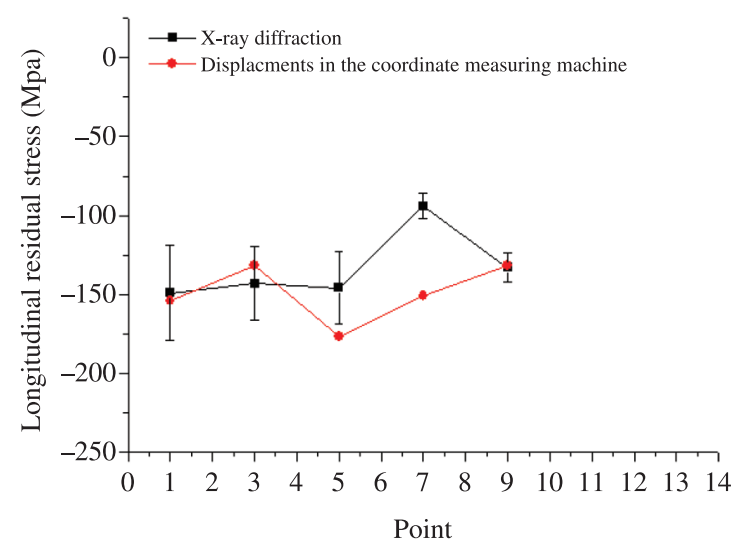

Figure 4. Longitudinal residual stresses obtained by X-ray diffraction and displacements in the coordinate measuring machine (as showed in graphic the uncertainty measurements are very small, so the points are not can be observed), points at a distance $2.5 \mathrm{~mm}$ from weld fillet.
Similar behavior was observed in points at a distance $5.0 \mathrm{~mm}$ from weld fillet. Values of transverse residual stress between -50 and $50 \mathrm{MPa}$ for coordinate machine measurements and between -175 and $-250 \mathrm{MPa}$ by X-ray measurements.

The results of the transverse residual stresses found by the two methods at all points in Figures 6 and 7 are outside the range of X-ray diffraction, showing that there is a need to study. Ongoing studies made in our laboratory revealed that the effects of anisotropy must be taken into account during the results analysis after the heat treatment for stress relief. For the transverse direction of welding, transverse also to the rolling direction of the plate, the results showed that the restoration of properties in this direction was not established because the low driving force for recrystallization ${ }^{12,13}$.

The discrepancy between these results suggested that new studies must be made to reduce the differences. Nevertheless simulation based on finite element method to determiner residual stress in welded joints presents similar discrepancy as compared by X-ray measurements 9 .

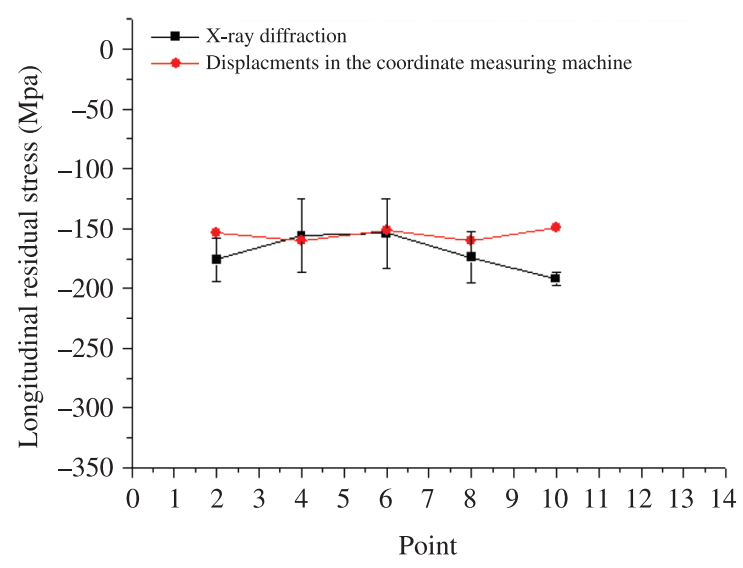

Figure 5. Longitudinal residual stresses obtained by X-ray diffraction and displacements in the coordinate measuring machine (as showed in graphic the uncertainty measurements are very small, so the points are not can be observed), points a distance $5.0 \mathrm{~mm}$ from weld fillet.

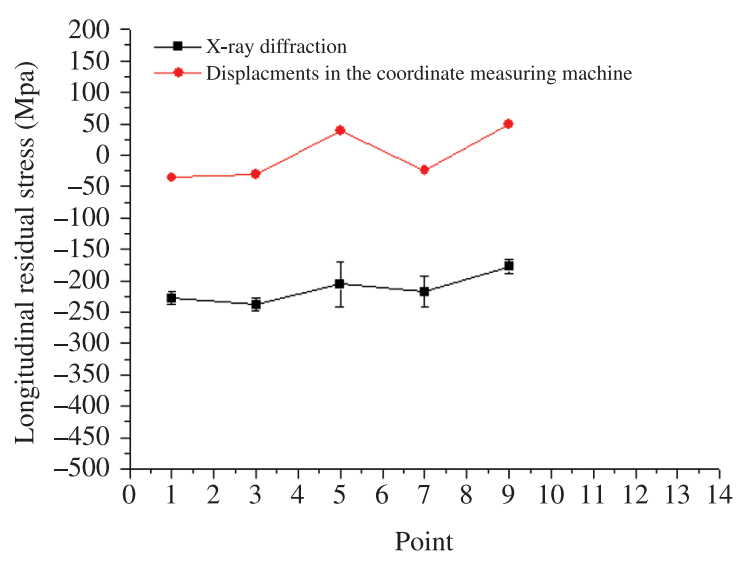

Figure 6. Transverse residual stresses obtained by X-ray diffraction and displacement in coordinate measuring machine (as showed in graphic the uncertainty measurements are very small, so the points are not can be observed), points a distance $2.5 \mathrm{~mm}$ from weld fillet. 


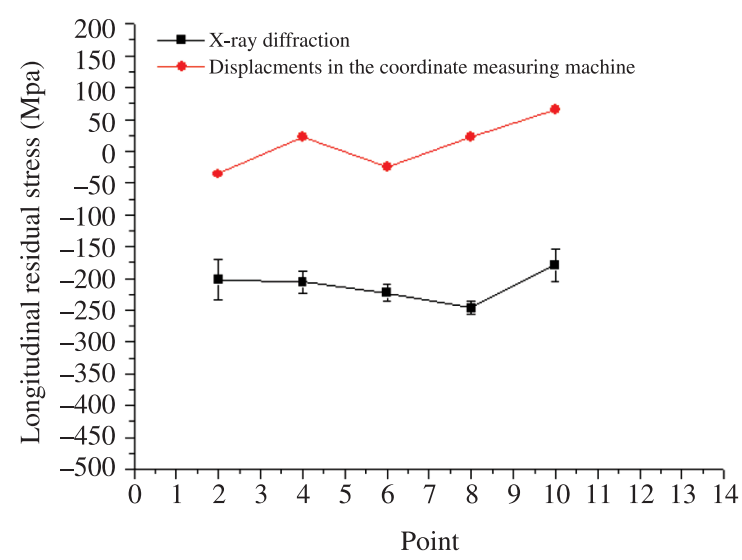

Figure 7. Transverse residual stresses obtained by X-ray diffraction and displacement in coordinate measuring machine (as showed in graphic the uncertainty measurements are very small, so the points are not can be observed), points a distance $5.0 \mathrm{~mm}$ from weld fillet.

Comparing the longitudinal stresses measured in points 1 to 10 in the heat affected zone, HAZ (Figures 4 and 5) with the Transverse residual stresses at the same points (Figures 6 and 7), we observe that the longitudinal stresses we obtain result very similar values absolute in both methods of measurements, whereas in transverse notes there is a

\section{References}

1. Lu J. Handbook of Measurement of Residual Stresses. SEM Inc.; 1996. 254 p.

2. Rodacoski MR. Medição de Tensões Residuais com Holografia Eletrônica. 2002.

3. Benning IO. Non-destructive determination of Load and Residual Stresses by the X-ray stress method. The Rigaku Journal. 1989; 6(2).

4. Bureau Veritas. Rules and Regulation for the Classification of Ships and Offshore Installation-Materials. Section 2. NR. 216DNCRO2E; 1997.

5. Mercantil Brasileira de Aço - MBA. Available from:: www.mba-aco.com.br/pdf/chapas_estruturas_navais_alta_ resistencia.pdf . Acess in: 11/03/2010.

6. American Welding Society - AWS. AWS A5.18: Specification for Carbon Steel Electrodes and Rods for Gas Shielded Arc Welding. AWS; 2001.

7. Lu J, Bouhelier C, Lieurade HP, Baralle D, Miege B and Flevanot JF. Study of Residual Welding Stress Using Stepby-step Hole Drilling and Xray Diffraction Method. Welding in the World. 1994; 33(2):118-128. similar behavior between the methods, but with divergence in values.

At points on the welding fillet (points 11, 12 and 13) it was shown that the stresses measured by the method of X-ray diffraction values are quite different from those obtained by the method of coordinate measuring machine. Measurements made by the method of X-ray diffraction showed inconsistent values, requiring new measurements to better observations.

\section{Conclusions}

The results obtained with the coordinate machine measurements proved to be quite consistent, as compared to values obtained by X-ray diffraction, especially for the longitudinal stresses.

The transverse residual stress present different values between the two methods. Although the difference between these methods showed similar behavior either for points at a distance $2.5 \mathrm{~mm}$ or $5.0 \mathrm{~mm}$ from weld fillet.

This new method showed satisfactory results, allowing a greater range of options for measurements in the residual stresses resulting from the welding process.

Acknowledgements

Thanks to FACEPE (Science and Technology Foundation of Pernambuco) and CNPQ (National Council of Research) for financial assistance during this work.

8. Okumura T and Tanigusgi C. Engenharia de Soldagem e Aplicações. Rio de Janeiro: Livros Técnicos e Científicos Ed.; 1982.

9. Callister Junior WD. Ciência e Engenharia de Materiais: Uma Introdução. 5. ed. Rio de Janeiro: Livros Técnicos e Científicos Ed.; 2002.

10. Guimarães PB, Pedrosa PMA, Yadava PY, Barbosa JMA, Siqueira Filho AV and Ferreira RAS. Determination of the Residual Stresses from a Temperature Field Numerically Obtained, 2012. In publication.

11. Oliveira GLG, Hélio CM and Jesualdo PF. Avaliação das Tensões Residuais em Tubos de Pequeno Diâmetro Soldados pelo Processo TIG Orbital. Soldagem \& Inspeção. 2009; 14(2). Available from: <http://www.scielo.br/scielo.php?pid=S0104$92242009000200003 \&$ script $=$ sci_arttext $>$. Access in: 23/08/2010. Comparative.

12. Lima EPR, Sanguinetti Ferreira, RA, Quadros NF and Yadava YP. Estudo dos aspectos cinéticos e mofológicos durante recristalização da liga AA8011. Revista Iberoamericana de Ingenharia Mecânica. 2006; 10(1):131-137.

13. Siqueira Filho AV, Guimarães PB, Pedrosa PMA, Yadava PY, Rolim TL and Ferreira RAS. Effect of Anisotropy in Heat Treatment Stress Relieving, 2012. In publication. 